\section{Haare als Proben}

W. G. Guder

München, Deutschland

Englischer Begriff hair as sample

Definition Verwendung von Haaren zum diagnostischen oder (häufiger) forensischen Nachweis von toxischen Substanzen oder Drogen.

Beschreibung Haare als diagnostische Proben sind geeignet, um den Zeitpunkt der Zufuhr eines Giftes, das in Haaren gespeichert wird', bzw. die Dauer der Einnahme illegaler Drogen nachzuweisen.

Dazu werden Haare am Ansatzpunkt abgeschnitten, nachdem sie an einer klebenden Fläche fixiert wurden (z. B. Tesafilm) und entsprechend deren Länge nach Waschen (um Kontaminationen von außen zu entfernen) in Segmente unterteilt, die je nach Fragestellung einer Woche, einem
Monat bis zu einem Jahr entsprechen (normales Wachstum der Haare $1 \mathrm{~cm} /$ Monat). Die Analyse ergibt dann eine Zuordnung der gefundenen Substanzen zum Zeitpunkt der Einnahme und ggf. Metabolisierung. Die Haarprobe wird in einer Kugelmühle zerkleinert und in organischen Lösungsmitteln (z. B. Methanol) extrahiert. Ein Aliquot des Extraktes wird mit GC-MS oder LC-MS analysiert. Auf diese Weise kann z. B. ein Drogenentzug nachgewiesen werden (bei Frage der Fahrerlaubnis nach Führerscheinentzug) oder die Dauer der Zufuhr eines Gifts in Monaten des Kalenders ermittelt werden. $\mathrm{Zu}$ Details und aktuellen Richtlinien s. Society of Hair Testing unter www.soht.org.

\section{Literatur}

Külpmann WR (2002) Klinisch-toxikologische Analytik. Verfahren, Befunde, Interpretation. Wiley-VCH, Weinheim

Medea B, Mußhoff F (2004) Haaranalytik. Technik und Interpretation in Medizin und Strafrecht. Deutscher Ärzteverlag, Köln 